Climate Policy 2(2002) 145-159

\title{
From Impacts Assessment to Adaptation Priorities: the Shaping of Adaptation Policy
}

\author{
Ian Burton, Saleemul Huq, Bo Lim, Olga Pilifosova, \\ Emma Lisa Schipper
}

\begin{abstract}
Under the United Nations Framework Convention on Climate Change (UNFCCC), adaptation has recently gained importance, yet adaptation is much less developed than mitigation as a policy response. Adaptation research has been used to help answer to related but distinct questions. (1) To what extent can adaptation reduce impacts of climate change? (2) What adaptation policies are needed, and how can they best be developed, applied and funded? For the first question, the emphasis is on the aggregate value of adaptation so that this may be used to estimate net impacts. An important purpose is to compare net impacts with the costs of mitigation. In the second question, the emphasis is on the design and prioritisation of adaptation policies and measures. While both types of research are conducted in a policy context, they differ in their character, application, and purpose. The impacts/mitigation research is orientated towards the physical and biological science of impacts and adaptation, while research on the ways and means of adaptation is focussed on the social and economic determinants of vulnerability in a development context. The main purpose of this paper is to demonstrate how the national adaptation studies carried under the UNFCCC are broadening the paradigm, from the impacts/mitigation to vulnerability/adaptation. For this to occur, new policy research is needed. While the broad new directions of both research and policy can now be discerned, there remain a number of outstanding issues to be considered.
\end{abstract}

\section{Adaptation in the framework convention}

The main purpose of this paper is to assess the evolution of adaptation research from its initial place as a handmaiden to impacts research in the mitigation context, up to its present emergence in a role crucial to the development of adaptation policy. On this basis, it becomes possible to identify the requirements that the next generation of adaptation research will have to meet. This development is already underway and can be further strengthened. While the broad new directions of both research and policy can now be discerned, there remain a number of outstanding issues to be considered, and the paper concludes with some relevant suggestions.

Adaptation is defined as "adjustment in natural or human systems in response to actual or expected climatic stimuli or their effects, which moderates harm or exploits beneficial opportunities" (IPCC, 2001: 72). Climate adaptation policy refers to actions taken by governments including legislation, regulations and incentives to mandate or facilitate changes in socio-economic systems aimed, at reducing vulnerability to climate change, including climate variability and extremes. Changes can be made in 
"practices, processes, or structures of systems to projected or actual changes in climate" (Watson et al., 1996).

Adaptation to climate change is an integral part of the United Nations Framework Convention on Climate Change (UNFCCC) in two related but distinct ways that relate to different policy domains. The first is the prevention of dangerous interference with the climate system by the stabilisation of greenhouse gas concentrations in the atmosphere, commonly referred to as "mitigation". The second is reduction of vulnerability to climate change by the process of "adaptation". The relationships are illustrated diagrammatically in Fig. 1. Both cases involve the science of impacts and their assessment.

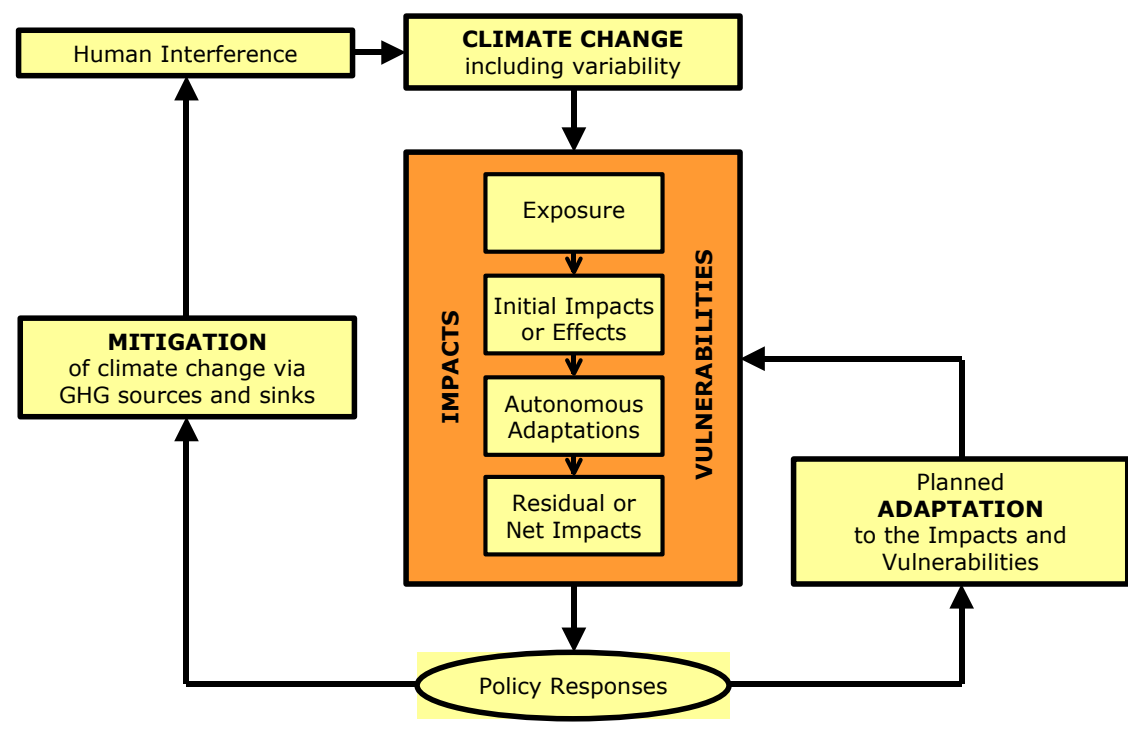

Fig. 1. Mitigation and adaptation responses to climate change (IPCC, 2001).

In the first case, it is crucial to assess the potential impacts of climate change because such assessments are an essential input to policy decisions about what constitutes "dangerous interference with the climate system". Prevention of dangerous interference is specified as the "ultimate objective" of the UNFCCC (Article 2). What matters in this connection is the extent to which the gross impacts of climate change can be reduced by adaptation. The growing scientific understanding of the probable net impacts of climate change is being used to inform policy makers in their task of making choices about the level of urgency in the political climate change negotiations, and therefore, the targets and schedules that need to be adopted if "dangerous interference" is to be avoided. Most research about adaptation as reported by the Intergovernmental Panel on Climate Change (IPCC) has been carried out in this "impacts and mitigation" context, and this is reflected strongly in the methodology employed. It is essentially directed to the "mitigation" side of climate policy. By implication, the greater the impacts the more need for mitigation. Furthermore, the greater the effectiveness of adaptation in reducing vulnerability to climate change, the less will be the urgency to be to reduce emissions of greenhouse gasses. Adaptation cannot prevent economic and other losses from climate change, but it can reduce and delay them (Smit and Pilifosova, 2001). Type 1 adaptation 
research essentially contributes to the debate about trade-offs between mitigation and adaptation.

The second way in which adaptation arises in the Framework Convention relates to development and related policy questions. The developed country parties to the UNFCCC have committed to "assist the developing country Parties that are particularly vulnerable to the adverse effects of climate change in meeting the costs of adaptation to those adverse effects" (UNFCCC, Article 4.4).

In order to inform the policy process about adaptation in this second context, the emphasis shifts from the question of gross and net impacts to questions about vulnerability, and how and where to deploy adaptation responses. These questions are important to the developing countries both because they wish to reduce their vulnerability to climate change in the most effective ways, and because they are essentially in competition with each other for whatever international funds may become available to help them meet the costs of adaptation. It is to the advantage of each country, therefore, to be able to show how vulnerable it is to climate change; how much adaptation policies and measures will cost; where it lacks sufficient capacity to adapt without external assistance; and generally how donor funds can be effectively used. Donor countries also have an interest in these questions because they wish to be reassured that their assistance in helping to meet the costs of adaptation will be money well spent, i.e. it will allow developed countries to meet their commitments to assist. The developed countries have shown less interest in their own need for adaptation, and have generally assumed that they have the financial and technical resources to adapt as and when necessary. To this extent, adaptation will only be seriously entertained in developed countries when it becomes evidently necessary.

Thus, there are two directions and purposes in adaptation research; adaptation research for mitigation policy, and adaptation research for adaptation policy. To date, the overwhelming preponderance of adaptation research has been conducted in response to the mitigation issue. This can be explained to a considerable extent by the predominance given to mitigation over adaptation in the text of the UNFCCC itself and in the negotiations leading up to the initial signing of the Kyoto Protocol in 1997. The interest of the policy makers and the requirements of the negotiations have been largely directed to mitigation. The interest in adaptation as a response has been comparatively low and often absent, and to the extent that it was present at all, it was in the context of mitigation debates. One important reason for this is that it is widely understood that in the long term adaptation will not suffice. The atmospheric concentrations of greenhouse gasses will have to be stabilised eventually at some tolerable level. More recently, however, the interest in adaptation as a legitimate policy response has increased, led by developing country negotiators. This has happened at least partly in response to a growing recognition that climate change is now occurring, impacts are being observed, and that even if fully implemented on time the Kyoto Protocol would only be a first small step towards achieving stabilisation of greenhouse gasses in the atmosphere. Some adaptation is now recognised as inevitable. The new challenge is to change the character of adaptation research from one that largely addresses the needs of the mitigation policy agenda, to one that also responds explicitly to the needs of adaptation policy. This requirement 
became manifest at the Sixth Conference of the Parties to the UNFCCC ${ }^{1}$ and was subsequently reinforced at the Seventh Conference of Parties (COP-7) in Marrakech in November 2001, where more attention was given to matters of adaptation, and agreement was reached in principle to establish three different funds, each with an adaptation component. Quite suddenly the need for better understanding of the requirements of adaptation policy has assumed a prominent place on the research agenda.

The research questions that need to be addressed are implicit in earlier decisions by the COP, especially Decision 11/CP.1 taken in Berlin as long ago as 1995.

Understanding this decision helps in the appreciation of the gulf between the impacts and mitigation orientation of what may be called the "first generation" of adaptation research and the policy orientation of the "second generation", now beginning. The first generation of studies mainly span over the 1995-2001 period and can be found in the 70 non-Annex I National Communications published to date (see UNFCCC National Communications, 2002 (website)).

From the outset of the climate change negotiations, some developing countries insisted on the need for adaptation, and the responsibility of the developed countries to help meet the costs of adaptation due to the historical record of emissions of developed countries. The small island nations at risk from sea level rise, and the least developed countries with low capacity to meet the costs of adaptation, were prominent among those making these demands. While agreeing to accept their responsibility to provide financial help in principle, donor countries were concerned that adaptation to climate change could become a bottomless pit, or a "black hole", absorbing a disproportionate amount of development assistance funds. Nor was it clear how adaptation funds could best be used. The COP-1 111 eeting in Berlin, therefore, formulated and adopted Decision 11/CP.1 in order to set in motion studies of adaptation, and laid out a broad timetable over which these studies would be conducted. These reflected, inter alia, the developed country view that adaptation was something for the future and that the immediate need was to prepare to adapt.

Adaptation was to be approached in three stages. The first stage was described as "short term" and the second and third stages as "medium to long term". They were defined as follows:

- Stage I: "Planning, which includes studies of possible impacts of climate change, to identify particularly vulnerable countries or regions and policy options for adaptation and appropriate capacity building."

- Stage II: "Measures, including further capacity building which may be taken to prepare for adaptation as envisaged in Article 4.1(e)."

- Stage III: "Measures to facilitate adequate adaptation, including insurance, and other adaptation measures as envisaged by Article 4.1(b) and 4.4."

The precise meaning of these definitions is open to interpretation, and there has been no further formal elaboration from the COP since 1995. The definition of Stage I is the clearest: studies on impacts, the identification of vulnerability and policy options as well as capacity building, are to be carried out. Stage II refers to preparation for

\footnotetext{
${ }^{1}$ COP-6 was held in The Hague in November 2000, and COP-6 bis in Bonn in July 2001.
} 
adaptation and Stage III to the facilitation of adaptation, but nowhere has it been explicitly agreed how adaptation policies or measures will be implemented.

According to some negotiators who participated in the drafting of Decision 11/CP.1, the ambiguity was unavoidable. Negotiators were not certain what they wanted to agree upon, and in 1995 it was assumed that Stages II and III would be delayed, perhaps long delayed.

The fact that adaptation was not seen as an immediate priority is reflected in the articles of the UNFCCC cited in the definition of the stages. Also, only in Article 4.1(b) of the UNFCCC is any reference made to implementation of adaptation, and this apparently refers to measures "to facilitate adequate adaptation", which may not mean necessarily to actually adapt.

Although a relatively slow progress towards adaptation seems to be implied in the three stages, it is clear that the focus was to be on adaptation policy (Stage I), as well as plans, programmes, measures, and capacity building. What Decision 11/CP.1 called for was adaptation studies for adaptation policy, and not adaptation studies for mitigation policy. Nevertheless the momentum of adaptation research to contribute to the impacts/mitigation debate was well established and much research continued with that aim. The international agencies including the United Nations Development Programme (UNDP), the United Nations Environment Programme (UNEP), the World Bank, as well as the research community in universities and non-governmental research centres have now begun to recognise the importance of adaptation research for adaptation policy as it was envisaged in Decision 11 of COP-1.

The Buenos Aires Plan of Action, adopted in 1998 to prepare for the future entry into force of the Kyoto Protocol, reflected increased demands of the developing countries to address climate change adaptation. It included a decision in principle to move to Stage II adaptation. The Marrakech Accords that emerged from COP- 7 went further and established two new funds (The Special Climate Fund and the Least Developed Countries Fund) under the UNFCCC to support, inter alia, "the implementation of adaptation activities where sufficient information is available". COP- 7 also adopted guidance for the operation of the Fund for Least Developed Countries (LDCs) to support the preparation of National Adaptation Programmes of Action (NAPAs) which "will serve as a simplified and direct channel of communication of information relating to the vulnerabilities and adaptation to climate needs of the least developing countries". A third fund, The Adaptation Fund, is to be established under the Kyoto Protocol by the imposition of a levy on the Clean Development Mechanism.

Before turning to an assessment of the "first generation" adaptation research it may be helpful to briefly report the definitions of three important concepts used in the adaptation literature.

\section{Concepts and definitions}

The report of Working Group II in the Third Assessment of the Intergovernmental Panel on Climate Change (McCarthy et al., 2001) provides definitions of three of the more important concepts employed in the climate debate: 


\subsection{Sensitivity}

Sensitivity is the degree to which a system is affected, either adversely or beneficially, by climate-related stimuli. Climate-related stimuli encompass all the elements of climate change, including mean climate characteristics, climate variability, and the frequency and magnitude of extremes. The effect may be direct (e.g. a change in crop yield in response to a change in the mean, range or variability of temperature) or indirect (e.g. damages caused by an increase in the frequency of coastal flooding due to sea-level rise).

\subsection{Adaptive capacity}

Adaptive capacity is the ability of a system to adjust to climate change, including climate variability and extremes, to moderate potential damages, to take advantage of opportunities, or to cope with the consequences.

\subsection{Vulnerability}

Vulnerability is the degree to which a system is susceptible to, or unable to cope with, adverse effects of climate change, including variability and extremes. Vulnerability is a function of the character, magnitude and rate of climate change and variation to which a system is exposed, its sensitivity, and its adaptive capacity.

These are "working definitions" subject to evolution as the science and the policy context change. For the purposes of this paper it is important to note how these concepts as currently defined lead to an enormous expansion of the factors that enter into climate adaptation policy. General adaptive capacity for example, can be seen as a function of wealth; population characteristics, such as demographic structure, education and health; organisational arrangements and institutions; and access to technology, and equity, to name only the most salient variables. More specific adaptive capacity relates to the specialised training, research, and institutions that are required as inputs to climate adaptation measures and policy.

One consequence of the move towards a second generation of adaptation studies has been the emergence of vulnerability as a central concept. A useful, if simplified, formulation is that vulnerability is a function of impacts and adaptation. Impacts depend upon the exposure of a system to climate and its sensitivity. Impacts are less where the climate is more benign (adequate and reliable rainfall, less frequent and severe extremes events such as tropical cyclones, heat waves and the like), and where systems are less sensitive or more robust (drought tolerant crops, buildings more resistant to wind damage). Adaptation depends upon the capacity of systems to adapt, and also on the will or intent to deploy adaptive capacity to reduce vulnerability. The mere existence of capacity is not itself a guarantee that it will be used (Burton and Lim, 2001).

Given the breadth of these concepts, and the need for adaptation policy, what is the record of adaptation research? What is the level and quality of adaptation science for adaptation policy? These questions are addressed in the following section. 


\section{First generation impacts and adaptation research}

The need for comparability has been a persistent theme in climate change research related to the UNFCCC. This applies at all levels from measurements to data, information, knowledge, and understanding. In a sense the whole of the IPCC enterprise is aimed at assuring comparability and trust in the science. This stems from the global nature of the climate change issue. It has been recognised from experience in other domains (acid precipitation and ozone layer depletion for example) that negotiations can best be advanced if the negotiators are working from a common understanding and acceptance of the underlying science. For this reason, it has become standard practice to develop and agree upon common methodologies to guide the research. The first guide for impacts and adaptation was written under the authority of the IPCC in the early 1990s (Carter et al., 1994; Parry and Carter, 1998). These IPCC Guidelines have been expanded and elaborated in the guidelines prepared for the United States Country Studies Program (USCSP) (Smith and Lazo, 2001) and also the United Nations Environment Programme (UNEP) Handbook on Methods for Climate Change Impact Assessment and Adaptation Strategies (Feenstra et al., 1998). These texts contain descriptions of many useful tools, methods, and guides to the literature, especially in the areas of climate change impacts studies. Taken together these guidelines and the ways they have been applied, has become known as the "standard approach", corresponding to what is referred to here as the "first generation" or Type 1 adaptation studies.

The essential character of the standard approach is contained in the seven steps of the IPCC Guidelines. These are listed as:

(1) Define problem (including study area, its sectors, etc.).

(2) Select method of assessment most appropriate to the problems.

(3) Test methods/conduct sensitivity analysis.

(4) Select and apply climate change scenarios.

(5) Assess biophysical and socio-economic impacts.

(6) Assess autonomous adjustments.

(7) Evaluate adaptation strategies.

The thinking behind these steps has its own internal logic. It is also highly condensed and omits or leaves implicit many other possible and useful "steps". For example, in order to assess future impacts of climate change it is not only necessary to think about future climate (climate scenarios), but also to consider the state of the systems that will be impacted, for example in socio-economic scenarios. The present and future condition of an economy (especially its vulnerability) is often a more powerful determinant of net impacts than projected climate change. Similarly Steps 6 and 7 both assume that adaptation responses are known, whereas in fact this is often not the case. Furthermore, it is important to note that the IPCC approach is impacts driven, rather than vulnerability driven, and this is reflected in the design of the steps.

A crucial feature of the standard approach is identified in Step 4, the selection and application of climate scenarios. By relying on climate change scenarios the standard approach directs attention to the impacts of future climate change and by default, away from current impacts and vulnerability. This orientation stems from a view of the issue as a pollution problem (like acid precipitation or stratospheric ozone layer 
depletion) that has to be addressed largely through the control of emissions. But climate change is not only a "pollution problem" related to the energy sector. It is also a broad development issue-a problem in which the whole character and values of human society on a global level and its future sustainable development are at stake. Economic growth and development, patterns and levels of consumption and lifestyle, are drivers of climate change, not simply emissions. Development has been taken into account on the emissions side of the climate issue by the creation of emission scenarios which are dependant on assumptions about population growth, per capita energy consumption, the "energy mix" in future supplies and changes in energy technology. The patterns and distribution of economic development has been given little consideration on the impacts and adaptation side, except as part of the global scenarios needed to project emissions.

Step 4 requires the selection of climate scenarios, or projections derived from Global Climate Models (GCMs), which are then imposed upon biophysical and socioeconomic systems usually through the use of models such as agro-meteorological crop models, or similar models for forest ecosystems or hydrological systems. Research along these lines has been very successful in producing a voluminous "impacts literature" summarised and assessed in the successive IPCC Assessment Reports (IPCC, 1990, 1995, and 2001). This literature is most impressive in the identification and assessment of biophysical impacts. It is less developed and less convincing in the case of socio-economic impacts, in part because less attention is given to socio-economic changes than to climate changes.

In applying the standard approach to many National Communications and "country studies" a common experience is that the overwhelming part of the time and funds allocated have been devoted to the selection and application of the climate scenarios and first order or gross impact studies. It is invariably noted that insufficient time was left to fully develop the adaptation component of the study. This has been widely reported in workshops organised under the UNDP-GEF National Communications Support Programme (NCSP), and elsewhere in the impacts literature.

From the position of seeking to advance the understanding and analysis of adaptation policy there are other limitations in the standard approach. There are at least five important explanations why models and climate scenario-based methods have not yielded useful results for the purposes of adaptation response and policy options.

First, by the time the analysis reaches Steps 6 and 7 researchers are faced with a battery of results that show a wide range of potential impacts of future climate conditions upon economy and society. There are substantial uncertainties in both the climate scenarios and future socio-economic conditions, and these uncertainties cascade forward into the impacts assessments. It is practically impossible, therefore, to specify with sufficient precision or in any meaningful way what it is that must be adapted to. Analysis of the choice of adaptation measures at some future time to an uncertain future climate in an unknown socio-economic context is bound to be highly speculative. This fact alone has served to discourage and delay serious interest in the development of adaptation policy on the part of the research and policy communities. It certainly does not capture the interest of either policy makers or practitioners in developing countries who are concerned with more pressing immediate and shortterm issues such as economic growth, productivity, and sustainable development: 
poverty alleviation and equity; public health, education, energy supply, efficiency and security; and related significant issues.

Second, the climate model projections themselves have two important constraints. Many adaptation measures are location or site specific, whereas the best climate scenarios provide information only for the globe and large regions. GCM scenarios are not sufficiently precise in terms of spatial resolution or scale for adaptation assessment. Downscaling is a technique that can be applied to climate projections in order to give more detailed local information, but at the same time accuracy tends to diminish (Hulme, 1996). Furthermore adaptation is driven more by variability and extremes of climate than by averages. Climate scenarios have the disadvantage of specifying mostly average conditions and for a few variables only. These are not the only variables that are important for adaptation decisions that often require information about combinations of different variables and forecasts of the duration of sequences of weather conditions. Climate change may lead to small changes in means and large changes in extremes. With more time and resources better models of future climate will no doubt be produced, but it is unclear how much improvement will be achieved and how soon. In the near term at least the design of adaptation measures is not likely to be much influenced by climate scenarios. Given these limitations, however, it should be noted that GCM scenarios can be applied to usefully identify a range of uncertainties for the purpose of strategic policy making.

Third, the impacts assessments themselves are not designed to consider a range of adaptation options, measures or strategies. For example, crop yields forecasts, which use crop growth models, can be useful in studying farm level adaptations such as the application of fertiliser, pesticides, irrigation and other capital inputs. They do not help in considering other adaptations, especially off-farm policies such as price supports or other market interventions, or changing land ownership and tenure systems.

Fourth, where adaptation has been incorporated into climate impacts studies it has been on the basis of assumptions about the adoption of possible measures. Commonly it is assumed that all of the theoretically available adaptation options will be used and that these will be instantaneously and effectively adopted by all the decision makers in question. In some studies (e.g. Rosenzweig and Parry, 1994), this assumption has been varied. Two possible levels of adaptation are assumed, partial adaptation (50\%) or full $(100 \%)$. The $50 \%$ assumption may mean that only $50 \%$ of the adaptation measures will be adopted, or that only $50 \%$ of the decision makers will adapt. The point here is that the assumptions are not based on any knowledge or understanding of the adaptation process itself. There has been little or no consideration of the social and behavioural or other obstacles in the adaptation process.

Fifth, because the standard approach has been developed for the scientific purpose of understanding impacts it pays less attention to the policy context of adaptation or to the key actors or stakeholders involved. The focus of the analysis is a top-down effort to understand impacts, rather than to find ways of reducing vulnerability by the development of policy options in association with stakeholders including those at risk.

Supporting evidence for limitations to the standard approach used in first generation impact and adaptation studies is found in research papers that have resulted from the 
US Country Studies Programme (Smith and Lazo, 2001) and the UNEP Country Studies (O'Brien, 2000) as well as in the reviews of literature in the report of the IPCC Third Assessment Report from Working Group II (McCarthy et al., 2001); in reports of workshops held under the UNDP-GEF National Communications Support Programme, (UNDP-GEF, 2000a,b,c); in reviews of the adaptation content of National Communications carried out by the UNFCCC secretariat; and in reports of the work of the Consultative Group of Experts on Initial National Communications from Parties not included in Annex I to the UNFCCC, (Earth Negotiations Bulletin, 2001).

In addition, a number of other comments and suggestions can be found in these documents:

- The content of National Communications is limited largely to discussion of biophysical impacts, and the initial identification of possible adaptation options in lists.

- Vulnerability and adaptation assessments are an optional component in National Communications.

- The guidelines for National Communications do not provide sufficient direction on vulnerability and adaptation assessments.

- The current knowledge of adaptation and adaptive capacity is insufficient for reliable prediction of adaptation, and is inadequate for rigorous evaluation of planned adaptation options, measures and policies.

This analysis of the first generation of impact and adaptation research provides a basis for the development of new guidelines and a new approach. This is not meant to suggest that the first generation of research has not been useful, nor that it should be discontinued. Scenario-driven impacts and adaptation studies in the context of mitigation policy negotiations are needed as much as ever, and must be expanded and improved. What is now needed is a second generation of studies to be conducted in parallel, and designed to meet the needs of adaptation policy development. The next section of the paper describes the requirements that the second generation of studies should attempt to satisfy.

\section{The development of a policy framework}

Adaptation research for policy is different in character from adaptation research in the impacts/mitigation context. Although both are conducted in a policy context and are being comparatively well supported for that reason, the impacts/mitigation variety of adaptation research includes more fundamental science, especially in biological and geophysical systems. This facilitates the development of that promote common methodologies and tools, and common standards of measurement. This is the purpose of the IPCC and other guidelines documents, already mentioned in the previous sections.

In the case of adaptation research for the reduction of vulnerability and related policies such a degree of top-down guidance is neither feasible nor desirable. Effective adaptation policy has to be responsive to a wide variety of economic, social, political, and environmental circumstances. A different kind of creativity and ingenuity is required. It is, therefore, inappropriate to provide guidelines in a 
prescriptive style. What is required is a common framework of concepts, linked together in a flexible manner that helps in the design and organisation of research for adaptation policy to reduce vulnerability. Given the experience with first generation impacts and adaptation research, and the needs of the policy process, the following framework is presented as a possible way to proceed. It draws in part upon work carried out under the UNDP-GEF National Communications Support Programme (Burton and Lim, 2001).

The lessons from the experience of the first generation of impact and adaptation studies, and the need for more policy-related results suggest many new requirements. These are best characterised in terms of a shift in emphasis from impacts to vulnerability. This leads us to ask the following questions: what is the nature of vulnerability? How is it to be measured or assessed? Is it possible to create a common yardstick for vulnerability? How can vulnerability best be reduced? What is involved in vulnerability reduction? What are the responsibilities of those considered to be most vulnerable, and those who intend to provide assistance for vulnerability reduction? A convergence of efforts is developing to address these questions (see for instance, Clark et al., 2000; Kelly and Agder, 2000; Klein and Nicholls, 1999; Ribot et al., 1996; UNEP, 2001).

While the current wave of interest in vulnerability is a welcome development in adaptation research, there is a certain danger that it will become an end in itself. The adaptation framework presented here, therefore, treats policy as the overarching purpose and the concept of vulnerability as subordinate to it.

The essential starting point is the present. This may seem to be self-evident. But in fact it differs from the standard impacts/mitigation research paradigm that begins with a consideration of future climate as characterised in climate scenarios. Policy-making starts with recognition of the need for policy innovations or changes in existing policy.

In order to ground adaptation in the present, the framework begins with an assessment of current policy. The standard approach in the first generation of adaptation research tends to assume that adaptation policy has to be created from scratch. This is because it is concerned with adaptation to climate change as characterised in climate scenarios. From a vulnerability and development perspective, however, it is clear that present day climate has impacts, both positive and negative. Human societies have always adapted to their climatic environment, and adaptation policy already exists, although it is rarely recognised by that name. A national government wishing to develop a policy for adaptation to future climate change might best begin, therefore, by assessing current vulnerability to present day climate including its variability and extremes, and the ways that existing policy and development practice serve to reduce vulnerability.

The assessment of current vulnerability requires answers to the following extensive set of questions:

- What has been the recent experience with climate variability and extremes?

- What economic damage has resulted and how has this been distributed spatially and among socio-economic groups? 
- What other non-economic impacts, such as social and environmental impacts, have occurred?

- Are there any trends in climate variability and extreme events, and if so to what can they be attributed?

- Are there are trends in damages and other impacts, and if so how can they be explained?

- What adaptation policies and measures have been used to reduce vulnerability and how successful have they been?

- What is the extent of adaptation in practice and what are the barriers, obstacles or incentives to adaptation?

- How does public policy (in any and all domains) affect impacts and adaptation?

- How does public policy with respect to climatic hazards relate to the economic and sustainable development policies and strategies in place?

- How do public policies with respect to climate hazards relate to policies for other atmospheric issues such as ozone layer depletion, acid precipitation, and air quality?

- How do public policies for atmospheric hazards relate to other natural resource management and environmental policies?

- To what extent have stakeholders (including those at risk) been involved in the policy development process, and how can this be facilitated?

Answers to these and related questions can be summarised and synthesised into an assessment of current vulnerability. This diagnosis also provides the basis for the compilation of an inventory of potential adaptation policy initiatives and reforms.

The next step in the policy development process involves the design of policy initiatives and alternatives, and their assessment and prioritisation. In order to conduct this exercise, account should be taken of what can be surmised about future conditions, including climate change and changes in the socio-economic environment. The questions to be asked largely mirror the questions about current vulnerability:

- In what ways is climate expected to change?

- What can be said about future climate variability and extremes compared with recent experience?

- What are the prospects for economic and sustainable development and how will this affect climate change impacts?

- What are the prospects for adaptation and how much can vulnerability be reduced?

- What are the constraints and limitations to public policy for adaptation?

- What are the costs of adaptation measures and what benefits can be anticipated?

- What will be the distribution of the benefits and costs of adaptation?

- What would happen in the absence of public policy reform and innovations?

- How does public policy for adaptation to climate change relate to other atmospheric, natural resource and environmental policies?

These questions provide the basis for the framework diagram (Fig. 2). The answers to the questions provide input to the policy process. The purpose of the framework 
diagram is not to present a prescription of policy or even policy development. It serves more in the nature of a checklist of things that should be taken into consideration in policy development. The only prescriptive elements are the admonitions to ground policy analysis in an assessment of current vulnerability, to take climate variability and extremes into account as well as changes in means, and to embed adaptation measures into development policy.

\begin{tabular}{|c|c|c|c|c|c|}
\hline \multicolumn{3}{|c|}{ I Assessment of Current Policy } & \multicolumn{3}{|c|}{$\begin{array}{c}\text { II Design of Policy Initiatives and } \\
\text { Alternatives }\end{array}$} \\
\hline \multirow{5}{*}{$\begin{array}{c}\mathbf{S} \\
\mathbf{T} \\
\mathbf{A} \\
\mathbf{K} \\
\mathbf{E} \\
\mathbf{H} \\
\mathbf{O} \\
\mathbf{L} \\
\mathbf{D} \\
\mathbf{E} \\
\mathbf{R} \\
\mathbf{S}\end{array}$} & \multirow[b]{2}{*}{$\begin{array}{l}\rightarrow \\
\rightarrow\end{array}$} & $\begin{array}{l}\text { 1. Socio-economic and } \\
\text { development context }\end{array}$ & $\begin{array}{l}\text { 1. Socio-economic and } \\
\text { development scenarios }\end{array}$ & $\rightarrow$ & $\begin{array}{l}\mathbf{A} \\
\mathbf{D}\end{array}$ \\
\hline & & $\begin{array}{l}\text { 2. Current policies and } \\
\text { management practices in } \\
\text { the natural resources and } \\
\text { environment sectors }\end{array}$ & $\begin{array}{l}\text { 2. Future resource management } \\
\text { and environmental trends and } \\
\text { objectives }\end{array}$ & $\rightarrow$ & $\begin{array}{l}\mathbf{A} \\
\mathbf{P} \\
\mathbf{T} \\
\mathbf{I}\end{array}$ \\
\hline & $\rightarrow$ & $\begin{array}{l}\text { 3. Current climate risks } \\
\text { including variability and } \\
\text { extremes }\end{array}$ & $\begin{array}{l}\text { 3. Future climate risk (change, } \\
\text { variability and extremes) }\end{array}$ & $\rightarrow$ & E \\
\hline & $\rightarrow$ & $\begin{array}{l}\text { 4. Current or baseline } \\
\text { adaptation assessment }\end{array}$ & $\begin{array}{l}\text { 4. Adaptation improvements } \\
\text { and innovations for climate } \\
\text { change }\end{array}$ & $\begin{array}{l}\rightarrow \\
\rightarrow\end{array}$ & $\begin{array}{l}\mathbf{A} \\
\mathbf{P} \\
\mathbf{A}\end{array}$ \\
\hline & $\rightarrow$ & $\begin{array}{l}\text { 5. Policies and measures } \\
\text { proposed to improve } \\
\text { current adaptation }\end{array}$ & $\begin{array}{l}\text { 5. Policy options and measures } \\
\text { and their evaluation }\end{array}$ & $\rightarrow$ & $\begin{array}{l}\text { C } \\
\text { I } \\
\text { T } \\
\text { Y }\end{array}$ \\
\hline
\end{tabular}

Fig. 2. Adaptation policy framework.

\section{The shape and content of adaptation policy}

At the end of the day, policy decisions are made by governments which have responsibility for the success or failure of the policies they adopt. The purpose of policy-related research for adaptation to climate change, as for other policy domains, is not to decide or advocate policy, but to provide the policy makers with policy choices, an analysis of the rationale of alternative policy choices, and additional information upon which they can base their judgements, Climate change adaptation can be a component in many different policy domains (Apuuli et al., 2000). Effective climate adaptation policy cannot be made on a "stand alone" basis, but has to be incorporated into other policies. For example, adaptation to climate change in agriculture should be a part of a broader agricultural policy. The same applies to, inter alia, forests, water resources, coastal zone management, public health natural ecosystems, infrastructure and human settlements, Relevant policies are not limited to such socio-economic sectors, but can also include policies for management of natural hazards and disasters (floods, droughts, tropical and extra-tropical storms, etc,), Governments may also have special policies that are directed to part of the country only, such as regional development policies, including rural and urban-centred regions, or particular river basins.

An assessment of current policy in agriculture, for example, will normally take into consideration the broad strategic objectives for agriculture in the national socio- 
economic and development context. Is the aim to expand commercial agriculture for export-led development? How much importance is given to local food security and the maintenance and improvement of agriculture-based livelihoods? Such policy directions inform choices throughout the agricultural sector that include matters of trade relations, duties, taxes, subsidies, and insurance. They also influence choice of crops, and many agricultural practices at the farm level. Of specific interest in the case of agriculture are other policies in related areas of natural resource and environmental management such as watershed protection and rehabilitation, soil erosion, soil salinity, the use of genetically modified crops and so forth.

Current climate risks are best assessed in the light of these related policies. Measures designed to reduce vulnerability to drought, or to other direct and indirect climate risks (e.g. floods, pest invasions, diseases, unseasonable frosts), will be less effective and can be counterproductive unless they are considered in this broader context. For example the introduction of irrigation into some regions of Africa has contributed to the spread of schistosomiasis.

A crucial element in the assessment of current policy is the review and evaluation of adaptation practices now in use, and the absence of others that might be used, but which are blocked or difficult to use for whatever reason. A description of current "adaptation baseline" can provide a benchmark against which to measure progress in the development and adoption of adaptation policy.

From an assessment of the successes and failures of current adaptation, new ideas and proposals are certain to emerge for better adaptation in the future. In many instances, improvements in adaptation (or the elimination of policies which tend to increase vulnerability) will yield net benefits to the economy or the agricultural system even in the absence of climate change. Policy innovations are especially desirable if they bring benefits under the present climate, which can be shown to bring greater benefits as the climate changes. The assessment of current policy, therefore, leads directly to policy initiatives and alternatives for climate change. Unlike the lists of adaptation measures, which have been suggested in first generation adaptation research, these policies are grounded in empirical studies of what has worked (and not worked) in the past.

\section{Suggested directions}

The evolution of climate adaptation research from its initial orientation towards the assessment of impacts for the purposes of mitigation policy to the emerging needs for adaptation policy, suggest some new directions and next steps. A broad approach to the development of adaptation policy has been described, and embodied in a flexible framework (Fig. 2). This framework should now be tested in a variety of locations. Such activities will require an elaboration of the framework, especially the preparation of some specific guidance on particular components. While there is most likely no need for a new and elaborate methods manual, some formulation of generic approaches would be useful. These might include socio-economic and development scenarios; assessments of climate risk, including alternative ways of characterising and measuring future climatic hazards in quantitative terms relevant for adaptation decisions; adaptation assessment including baseline adaptation; and the evaluation of possible future policies and measures. 
The framework may also be helpful as part of a new round of enabling activities under the UNFCCC to assist in the preparation of second National Communications by developing countries; the preparation of NAPAs, and to carry out the studies proposed in Stage II adaptation. These should be based on the knowledge and experience gained from the first generation of studies, as well as the post-first generation studies done in selected regions and countries, such as the Caribbean, and Pacific islands (World Bank, 2000b) and Bangladesh (World Bank, 2000a). Although not done under a common methodological framework, these studies have nevertheless taken the adaptation analysis forward in a more adaptation policy direction, and results need to be incorporated into any second generation of adaptation analysis and research.

A critical question to be addressed in the design of second generation studies concerns the quality and the rigour of the analysis. There is a sense of urgency especially in the most vulnerable countries, leading to demands for prompt action. In some cases the adaptation policies and measures needed may be very evident, and further delay in design and implementation while studies are carried out may not be defensible. On the other hand, the situation in many countries is that there is insufficient knowledge or information upon which to base good policy choices. For example, one concern increasingly being expressed is that it would be comparatively easy to allocate adaptation funds to "concrete" or hard adaptations of an engineered and structural kind. It cannot be safely assumed that such adaptation policies and measures would be the most cost-effective in reducing vulnerability to climate change, and there are reasons to suppose that such measures could have counterintuitive results, by serving to increase vulnerability. This is the challenge faced by the teams that will prepare the National Adaptation Plans of Action, and by studies that are currently in the planning stages for Central America and Mexico, the Caribbean, the south Pacific, some regions of Africa, and elsewhere.

Climate change impacts are not yet truly severe. The consequences are likely to be incremental and cumulative. There is, therefore, a case to be made for taking the time for sufficient policy analysis and development before taking decisions that could prove to be seriously wrong. At the same time, there are many instances where present day climate variability and extremes are now exacting a heavy toll on development. In such cases, with or without climate change, there is need for more urgent anticipatory action.

\section{References}

Apuuli, B., Wright, J., Elias, C., Burton, I., 2000. Reconciling national and global priorities in adaptation to climate change with an illustration from Uganda. Environ. Monitor. Assess. 61, 145-159.

Burton, I., Lim, B., 2001. Adaptation Policy Framework, Draft Report, UNDP, New York.

Carter, T.R., Parry, M.L., Harasawa, H., Nishioka, S., 1994. IPCC Technical Guidelines for Assessing Climate Change Impacts and Adaptations with a Summary for Policy Makers and a Technical Summary. Department of Geography, University College London, UK and the Centre for Global environmental Research, National Institute for Environmental Studies, Japan. 
Clark, W.C., Jaeger, J., Corell, R., Kasperson, R., McCarthy, J.J., Cash, D., Cohen, S.J., Desanker, P., Dickson, N.M., Epstein, P., Guston, P.H., Hall, J.M., Jaeger, C., Janetos, A., Leary, N., Levy, M.A., Luers, A., MacCracken, M., Melillo, J., Moss, R., Nigg, J.M., Parry, M.L., Parson, E.A., Ribot, J.C., Schellnhuber, H., Schrag, D.P., Seielstad, G.A., Shea, E., Vogel, C., Wilbanks, T.J., 2000.

Assessing Vulnerability to Global Environmental Risks, Report of the Workshop on Vulnerability to Global Environmental Change: Challenges for Research, Assessment and Decision making. Airlie House, Warrenton, Virginia (December 2000), Environment and Natural Resources Program, Belfer Centre for Science and International Affairs (BCSIA), Kennedy School of Government, Harvard University, Cambridge, MA.

Earth Negotiations Bulletin (ENB), 2001. Summary of the Inter-Regional Workshop of the Consultative Group of Experts on Initial National Communications from Parties not Included in Annex I to the UNFCCC. International Institute for Sustainable Development, New York, 19-22 March 2001. I. Burton et al. / Climate Policy 2 (2002) 145- 159159

Feenstra, J.F., Burton, I., Smith, J.B., To1, R.S.J. (Eds.), 1998. Handbook on Methods for Climate Change Impact Assessment and Adaptation Strategies, Version 2.0. UNEP/IVM, The Netherlands.

Hulme, M. (Ed.), 1996. Climate Change and Southem Africa: An Exploration of Some Potential Impacts and Implications in the SADC Region. A Report Commissioned by WWF International and Co-ordinated by the Climatic Research Unit, UEA.

IPCC (Intergovernmental Panel on Climate Change) Climate Change 2001: Impacts, Adaptation, and Vulnerability, Summary for Policymakers and Technical Summary of the Working Group II Report. IPCC, Geneva.

Kelly, P.M., Agder, W.N., 2000. Theory and practice in assessing vulnerability to climate change and facilitating adaptation. Clim. Change 47, 325-352.

Klein, R.J. T., Nicholls, R.J., 1999. Assessment of coastal vulnerability to climate change. Ambio 28, 182-187.

McCarthy, J.J., Canziani, O.F., Leary, N.A., Dokken, D.J., White, K.S., 2001. Climate Change 2001: Impacts, Adaptation, and Vulnerability-Contribution of Working Group II to the Third Assessment Report of the Intergovernmental Panel on Climate Change. Cambridge University Press, Cambridge.

National Communications Support Programme, (NCSP) 2000a. Workshop Report: thematic Workshop on Vulnerability and Adaptation Assessment. Chisinau, Moldova, UNDP-GEF, New York, 26-28 January 2000.

NCSP, 2000b. Workshop Report: Thematic Workshop on Vulnerability and Adaptation Assessment. Amman, Jordan, UNDP-GEF, New York, 7-9 March 2000.

NCSP, 2000c. Workshop Report: Thematic and Regional Training Workshop on Vulnerability and Adaptation to Climate Change-English Speaking African Countries. Nairobi, Kenya, UNEP, Nairobi, 4-7 July 2000.

Parry, M., Carter, T., 1998. Climate Impact and Adaptation Assessment. Earthscan Publications, London.

Ribot, J.C., Magalhaes, A.R., Panagides, S.S. (Eds.), 1996. Climate Variability, Climate Change and Social Vulnerability in the Semi-Arid Tropics. Cambridge University Press, Cambridge, UK.

Rosenzweig, C., Parry, M.L., 1994. Potential impact of Climate Change on World Food Supply. Nature 367,133-137. 
Smith, J.B., Lazo, J.K., 2001. A summary of climate change impact assessments from the US Country Studies Program. Clim. Change 50 (1/2), 1-29.

Smit, B., Pilifosova, 0.,2001. "Adaptation in the Context of Equity and Sustainable Development", IPCC Second Assessment Report. Cambridge University Press, Cambridge, UK, Chapter 18.

O'Brien, K. (Ed.), 2000. Developing Strategies for Climate Change: The UNEP Country Studies on Climate Change Impacts and Adaptations Assessment, Report 2000-02. CICERO, Oslo, Norway.

UNEP, 2001. Downing, T.E., Butterfield, R., Cohen, S., Huq, S., Moss, R., Rahman, A., Sokona, Y., Stephen, L., 2001. Vulnerability Indices, Climate Change Impacts and Adaptation. UNEP Division of Policy Development and Law, Nairobi.

UNFCCC National Communications, see http://www.UNFCCC.int.

Watson, R. T., Zinyowera, M.C., Moss, R.H. (Eds.), 1996. Climate Change 1995:

Impacts, Adaptations and Mitigation of Climate Change: Scientific- Technical Analyses Contribution of Working Group II to the Second Assessment of the Intergovernmental Panel on Climate Change. Cambridge University Press, Cambridge, UK.

World Bank, 2000a. Bangladesh Climate Change and Sustainable Development, Report No. 21104-BD. Rural Development Unit, South Asia Region, World Bank, Washington, DC.

World Bank, 2000b. Adapting to Climate Change, Cities, Seas, and Storms: Managing Change in Pacific Island Economies, Vol. IV. World Bank, Washington, DC. 